\title{
Prostate Cancer pN0 TNM Finding v8
}

National Cancer Institute

\section{Source}

National Cancer Institute. Prostate Cancer pNO TNM Finding v8. NCI Thesaurus. Code C140159.

Prostate cancer with no positive regional nodes. (from AJCC 8th Ed.) 